\title{
Challenge Agent Supplier Address
}

National Cancer Institute

\section{Source}

National Cancer Institute. Challenge Agent Supplier Address. NCI Thesaurus. Code C158302.

The address of the person, company, organization, or institution that supplied the challenge agent employed in the study model. 